\title{
Composing Songs for Teaching Science to College Students
}

\author{
Yee Pinn Tsin, Isabel \\ Sunway College, Jalan University, Malaysia
}

Copyright (C) 2015 by authors, all rights reserved. Authors agree that this article remains permanently open access under the terms of the Creative Commons Attribution License 4.0 International License

\begin{abstract}
Recent studies have shown that songs may enhance learning as they function as mnemonic devices to increase memorability. In this research, songs based on the more difficult subtopics in Chemistry were composed, encompassing many formulas, equations and facts to be remembered. This technique of song composition can be used in any subject, any point of time and any tune can be used. Songs can be utilized for any class size, from tutorials to lecture halls. It was found in this study that students understood and retained key information better. In addition, songs added variety to classroom learning experiences, lowered students' stress levels, increased enjoyment and engaged students more effectively by catering for students with different learning styles.
\end{abstract}

Keywords Songs, Classroom Learning, College Students

\section{Introduction}

Songs have been a major source of entertainment worldwide that transcends culture, race and religion. It has been known to evoke strong emotions, which can enhance some aspects of memory [1]. Therefore, this may help our students memorize important facts, formulas and concepts.

This technique of song composition using popular tunes appeals to our college learners as it engages students through multiple modalities namely auditory, kinesthetic and visual learning styles [2]. Any tune could be used, as long as it was familiar to students. This methodology has been tried for students in Pre-University, Diploma, and in training sessions for Academic and non-Academic staff. Most of the tunes used in my research originated from Disney cartoons as animations are favorites among the young and old alike.

This methodology has support in physiological, neurological and behavioral studies to reduce stress in students [3]. Research has shown that music reduces blood pressure, heart rate and body temperature in students [4] and these may be indicative of reduced levels of anxiety. In
Russell's [5] investigation, he studied the effectiveness of using music in anxiety reduction among 265 university students. His results indicated that using music for highly anxious students might be an effective and alternate method for reducing anxiety. It has even been used by luminary people such as National Institutes of Health (NIH) Director Francis Collins, who occasionally sang to students at the University of Michigan to break up the monotony [6]. Governer and co-workers (2013) discovered that using science-content songs had relevance from a constructivist approach as it could help students construct the meaning of science concepts. They had supporting data that showed that songs had a socio-cultural perspective in terms of student engagement and also from a cognitive perspective as students were able to make connections in learning [7]. Although there is concrete conception of the value of teaching using songs, teachers may have difficulties in selecting songs. Hence, good and interesting song materials can be provided to overcome such a problem [8].

Generally, students find studying science subjects academically rigorous, intellectually stimulating and potentially frustrating especially for those who are academically weak. In addition, the learning styles of college students nowadays are mostly visual and kinesthetic, rather than auditory. Therefore, there needs to be innovation in traditional teaching that can cater for our 21 st century college students that have such diverse learning styles and short attention spans due to speed and advancement in everyday technology. The objective of this study is to gather data on the effectiveness of using songs to complement current pedagogical techniques. It aims to obtain feedback if this method of song composition can assist students of different academic caliber.

\section{Materials and Methods}

Research was conducted on ninety five Monash University Foundation Year (Science) students in Sunway College for the duration of two semesters. By referring to the syllabus of a chosen subtopic, a song could be written 
based on important key concepts and principles. After teaching the concepts, the song was displayed on Microsoft PowerPoint slides. Students were informed that the song was already uploaded onto the Chemistry student portal for them to view the soft copy of the song anytime, anywhere. The lyrics of the song would be sung after informing them of the origins of the tune.

It was expressed that students could practice singing it anytime, anywhere. A questionnaire, consisting of six closed questions was administered during class time. The design of the questionnaire began with a data analysis plan such as every question had a purpose and should produce the best possible data for the purpose of this action research. The questions had to be very clear such that there was no misinterpretation and to make it easy for students to provide valid, accurate, and reliable answers. In addition, the questions designed had to fulfil content validity to ensure that the sample questions was measuring what was intended to be measured [9].

Students were given approximately 5-10 minutes to complete the questionnaire and to add in any additional comments. They were not requested to write down their names in the forms, hence there was a level of anonymity and they were able to write down their opinions without fear. A frequency count was done for each question and figures were used to present the findings. The results of the questionnaire were analyzed and categorized.

Additional studies could be done to include a more

comprehensive questionnaire with a greater addition of open ended questions. In addition, more varieties of songs could be composed using different tunes such as rap, pop or jazzy tunes. This is to add variety to the repertoire of song genre as most of those currently used originated from Disney animations. A sample of a song used to teach a subtopic in Chemistry called, "Equilibrium" is shown below and the tune, "Colours of the Wind" is from the Disney movie called Pocahontas.

\section{Equilibrium Song}

A system at equilibrium is dynamic, The concentration of products and reactants, They'll always and forever be a constant, Rate of forward, reverse reactions will be same.

Kc calculations are popularly tested,

$\mathrm{Kc}$ tells us how far a reaction occurs, If $\mathrm{Kc}$ is much smaller than the value of 1 , This means there is very little product formed.

\section{Chorus}

Le Chatelier's Principle is so important, When Temperature of the system increases, The equilibrium, it will shift to endothermic.

\section{Results}

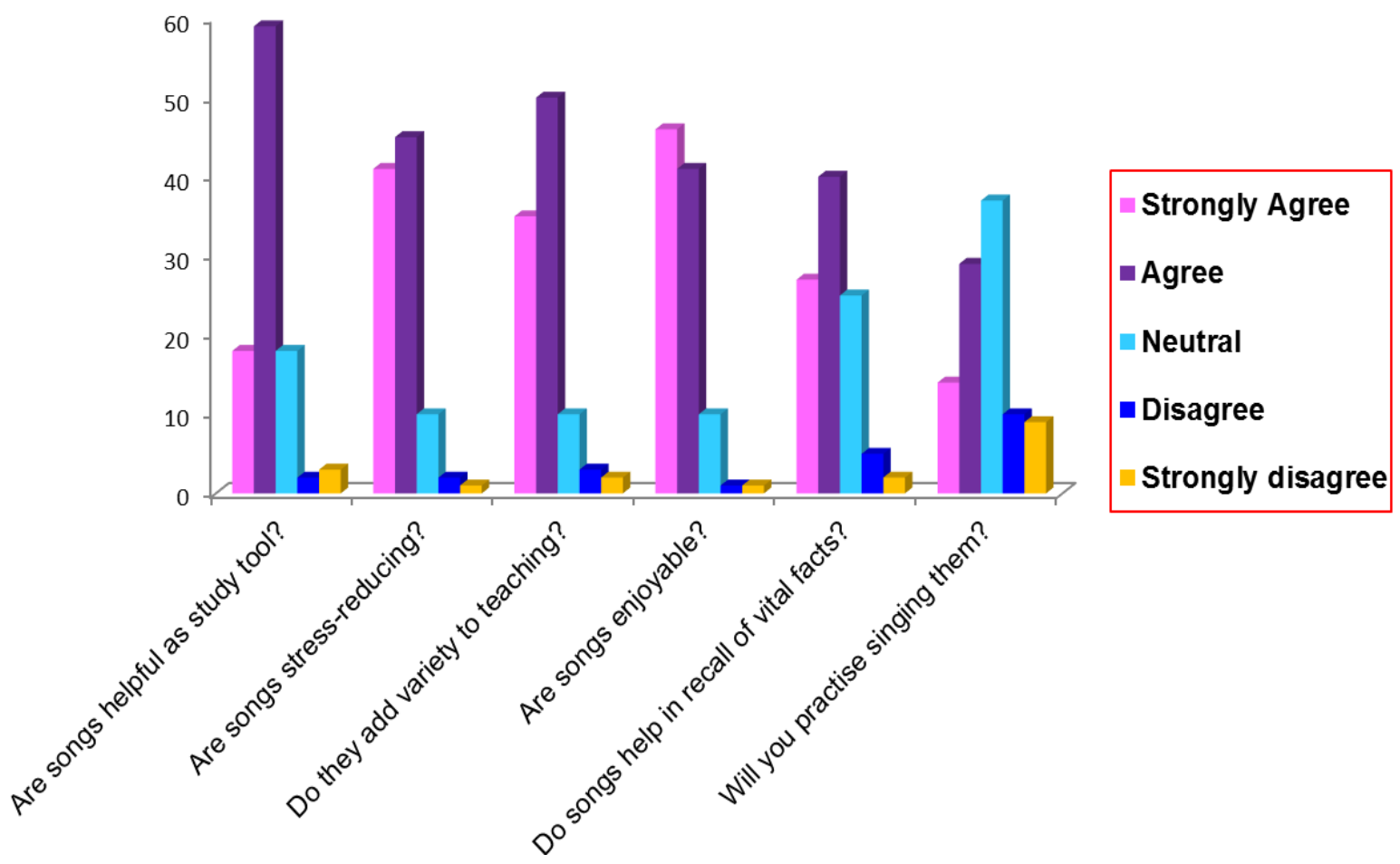

Figure 1. Analysis of questionnaire results based on action research conducted on ninety five Monash University Foundation Year (Science) students. A questionnaire, consisting of six closed questions was administered: 1) Are songs helpful as a study tool? 2) Do you find songs stress-reducing? 3) Do songs add variety to teaching? 4) Are using songs enjoyable in the classroom? 5) Do songs help in recall of important facts? 6) Will you practice singing the songs repeatedly? The results of the questionnaire were analyzed and displayed in a chart. The research was repeated with two independent set of students on different days. 


\section{Discussion}

The college students from the Monash University Foundation Year needed songs to help as teaching aids and as a supplementary form of pedagogical instruction. They are $21^{\text {st }}$ century learners that can easily learn through music and other auditory form of stimulation. The active research found that a majority of the students $(87 \%)$ rated that songs were enjoyable in the classroom. It lowered their stress $(86 \%)$ and boredom levels and they understood and retained key information better. It was observed that attendance, rapport and punctuality also increased significantly after utilizing science songs to teach college students. They wrote comments that they appreciated the efforts and time taken to compose such songs and they thoroughly enjoyed the variety in learning that they experienced. In addition, they looked forward to each class as they wanted more songs to be composed and sung in class. This is corroborated from the results in Figure 1 that $85 \%$ of students surveyed revealed that songs added variety to teaching and learning. Further analysis of data demonstrated that students agreed that songs were helpful as a study tool (77\%) and that it assisted their learning (67\%).

Research from Wolters and Rosenthal [6] concurred that students who were unwilling to read a textbook chapter might listen to a related song repeatedly. However, $19 \%$ of the students stated that they would not practice singing the songs repeatedly. This could be attributed to the fact that most of the songs composed were based on Disney cartoon tunes and hence, only slightly more than half of total students (54\%) surveyed showed that Disney tunes appealed to them while $16 \%$ of them revealed that such tunes did not particularly appeal to them. It could be possible that the majority of male students would prefer other song types and not from cartoons.

As such, there were requests for more composition of songs on covers from Taylor Swift, Carrie Underwood, male artistes and other contemporary music artistes. This could be an area for future research, whereby the type of songs, a bigger number of participants and a more comprehensive questionnaire could be carried out.

Nevertheless, this methodology can be applied at strategic points for all subjects to supplement the curricula with music. As students could remember lyrics of songs upon listening to them repetitively, they could recall important facts, equations and concepts easier from song lyrics $(67 \%)$. Crowther [2] confirms this by stating that songs are organizational mnemonic devices. Results from this study support previous research that song composition appeals to our college students as it engages them through multiple modes (verbal vs nonverbal) and modalities namely auditory, kinesthetic and visual learning styles [2].

\section{Conclusions}

There was positive feedback from college students in the teaching of Science with songs as it appealed to them, helped them recall vital concepts, added variety to their classroom learning and lowered their stress levels. In addition, this technique increased students' enjoyment and engaged them more effectively by catering for students with different learning styles as they are a generation of 21 st century learners that love music and variety in their learning process.

\section{Acknowledgements}

I would like to express my most sincere appreciation to the 95 Monash University Foundation Year students in Sunway College for their time and efforts in completing the survey.

\section{REFERENCES}

[1] Levine LJ, Edelstein RS. (2009). Emotion and memory narrowing: a review and goal-relevance approach. Cognition Emotion, 23, 833-875.

[2] Crowther G. (2012). Using science songs to enhance learning: an interdisciplinary approach. CBE Life Sci. Educ., 11(1), 26-30. doi: 10.1187/cbe.11-08-0068.

[3] Albers BD, Bach R. (2003). Rockin' soc: using popular music to introduce sociological concepts. Teach Sociol., 31, 237-245.

[4] Savan A. (1999). The effect of background music on learning. Psychol Music, 27, 138-146.

[5] Russell LA. (1992). Comparisons of cognitive, music, and imagery techniques on anxiety reduction with university students. J Coll Stud Dev., 33, 516-523.

[6] Anonymous. (2011). Francis Collins sings to the 2011 Genetic Counseling graduates.

https://www.youtube.com/watch?v=ob-r5MPa-ms (accessed 2015).

[7] Governor D, Hall J, Jackson D. (2013).1.Teaching and Learning Science Through Song: Exploring the experiences of students and teachers. International Journal of Science Education, 35, 3117-3140.

[8] Yau, Andrew (2015). Malaysian Teachers' Perspective on using songs in English Language teaching. International Journal of Social Science and Humanity 5, 87-89.

[9] Vannette, DL (2014). Questionnaire Design: Theory and Best Practices. Retrieved from

https://css-center.stanford.edu/sites/default/files/Questionnai re\%20Design\%201.pdf

[10] Wolters CA, Rosenthal H. (2000). The relation between students' motivational beliefs and their use of motivational regulation strategies. Int J Educ Res., 33, 801-820. 